\title{
Peer Teaching with Root Cause Analysis Method in Increasing Obedience Reporting of Patient Safety Incident
}

\author{
Harlina Putri Rusiana $^{1^{*}}$, Tri Kurniati ${ }^{1}$, and Abdul Aziz Alimul Hidayat ${ }^{2}$ \\ ${ }^{I}$ Faculty of Nursing, University of Muhammadiyah Jakarta, Indonesia \\ Jalan Cempaka Putih Tengah I/1, Kota Jakarta Pusat, DKI Jakarta 10510 \\ ${ }^{2}$ Lecturer in Faculty of Nursing, University of Muhammadiyah Surabaya, Indonesia \\ Jalan Raya Sutorejo No. 59, Mulyorejo, Kota Surabaya, Jawa Timur 60113 \\ "Corresponding author: harlinarusian@gmail.com
}

\begin{abstract}
Background: Reporting of Patient safety incident is very important for nurses in hospitals. The RCA (Root Cause Analysis) method in its application has an impact on improving knowledge about incidents, learned in identifying problems, and forming on achievement targets and improved peer communication skills. RCA mechanism is not widely known by the nurse. Peer teaching method is considered effective as a learning method with themselves. Objectives: This study aim were to determine the effect of Peer Teaching with RCA methods on obedience of patient safety incident reporting by nurses, including compliance, identification and internalization categories. Method: This study design is pre experiment with three times measurement. It is a Pre intervention, Post Intervention I and II. The study was conducted in Mataram hospital with 51 samples of Diploma and Professional nurses, at least one year of working period. Sampling technique is Purposive sampling. The data analysis used is Wilcoxon Test. Results: In all obedience indicators, there were differences in pre intervention score with post intervention I in the compliance category ( $p$ 0,000), identification category ( $p$ 0.004), internalization category $(p 0.028)$ and the compliance category $(p 0,000)$ in post intervention II. Conclusions: There are differences in compliance scores (compliance, identification and internalization categories) on the reporting the patient's safety incident prior to after given peer teaching on post intervention I and compliance indicator on post intervention II. So it is important to keep peer teaching be improve nurse obedience in the identification and internalization categories
\end{abstract}

Keywords: Obedience; Patient safety incidents reporting; Peer Teaching; RCA methods.

\section{INTRODUCTION}

The reporting of patient safety incident represents a part of the patient safety program. At the hospital level, it is conducted to know the cause of patient safety incident to the problem root as anticipation so that the incident is not re-recurred. Disobediently in conducting the registry and reporting are related failures of the incident that happened. This matter will cause the study process for nursing amelioration toward patient becomes inhibited.

Disobediently of reporting is caused due to the nurse which has the out of reason fear caused by the nurse ignorance about the quality of patient safety implementation especially when adverse event happened and involve the Root Cause Analysis (RCA) team. Root Cause 
Analysis (RCA) is one of the methods in tracing the cause of a problem and its result can be the recommendation on correcting the hospital service system (Ministry of Health, 2008).

The implementation of Root Cause Analysis is requiring the increase of knowledge, the ability to identify the problem, the identification of latest authority, the involvement directly in cases, the ability to measure the result achievement, and the communication inter-colleague become a nurse's contribution in increasing the quality of patient safety (Charles et al, 2016).

However, based on the RCA implementation in the hospital, only a few of them who are concerned. Even the executor nurse does not know the concept of RCA. Due to the target of competency which must be owned by the executor nurse, it is expected that a nurse can understand the importance of RCA method through the peer study to increase the knowledge so that nurses are dare to report (Hwa, 2009; Health, 2012). The aim of this research is to learn the influence of Peer Teaching of Root Cause Analysis (RCA) method toward the obedience of executor nurse on reporting the patient safety incident in Mataram Hospital.

\section{METHOD}

The research design is pre experiment with the One Group Pre-Post Test. The population in this research is executor nurses in inpatient room of Mataram Hospital with the level of education are diploma 3 of Nursing and Nurse of 106 people. The samples are 51 nurses according to the criteria of inclusion that is minimum 1 year of service. Sampling is done by the Purposive Sample technique.

The independent variable is Peer Teaching of Root Cause Analysis (RCA) method, and the dependent variable is the obedience on reporting the patient safety incident (included compliance, identification and internalization categories) (Niven, 2012). The data obtained from this study is sourced from the distribution of questionnaires, the sheet of document search of the room head and patient/ patient's family. The pre-test is done once before intervention, and the post-test is done twice in the range of 40 days. Analysis which is used for the univariat is the frequency of distribution, whereas bivariate analysis were using statistical test of Wilcoxon with the significant differences of $\alpha \leq 0.05$. The control of research bias is done by doubled linear of regression test.

The questionnaires research is divided into four parts. The first parts were contained the characteristic of respondent including gender, ages, the last education, and year of service. The second parts contained with 37 questions (likert scale) depicting the nurse compliance report of the patient safety incident with three indicators (compliance (4), identification (7), and internalization (26)). The third parts were sheets of search event (Guttman scale) which is addressed to the patient or patient's family. The fourth parts were sheets of search reporting which is addressed to the room head. This sheet was a list of the patient safety incident which is divided into 40 subtypes of incident reported by executor nurses/ respondents in the last of 20 days (Ministry of Health, 2008).

\section{RESULT AND DISCUSSION}

Table 1 indicates that the mean of respondent ages is 25.88 years, with the mean of length of working is 1.8 years. Female respondents are 39 respondents $(76.5 \%)$, and respondent with education level of diploma 3 of Nursing are 30 respondents (58.8\%). 
Table 1 Characteristic of Respondent $n=51$

\begin{tabular}{clcccc}
\hline No & \multicolumn{1}{c}{ Characteristic } & Mean & SD & n & \% \\
\hline 1 & Ages & 25.88 & 2.197 & & \\
2 & Length of working & 1.8 & 1.327 & & \\
3 & Gender & & & 12 & 23.5 \\
& a. Male & & & 39 & 76.5 \\
& b. Female & & & \\
4 & Level of education & & 30 & 58.8 \\
& a. Diploma 3 of Nursing & & 21 & 41.2 \\
\hline
\end{tabular}

Table 2 indicates the highest mean of obedience of executor nurse reporting score is at the Post Intervention I of indicator of compliance (83.82), identification (91.49), and internalization (92.02). Whereas the lowest mean of obedience of executor nurse reporting score is at Pre Intervention of indicator of compliance (67.71), identification (85.06), and internalization (87.82).

Table 2 Mean of Obedience of Executor Nurse in reporting the patient safety incident before and after Peer Teaching conducted in Mataram Hospital of the year 2017, $n=51$

\begin{tabular}{lcccccccccccc}
\hline \multicolumn{1}{c}{$\begin{array}{l}\text { Variable of } \\
\text { Obedience }\end{array}$} & \multicolumn{4}{c}{ Pre Intervention } & \multicolumn{4}{c}{ Post Intervention I } & \multicolumn{3}{c}{ Post Intervention II } \\
\cline { 2 - 13 } & Min & Max & $\bar{x}$ & Me & Min & Max & $\bar{x}$ & Me & Min & Max & $\bar{x}$ & Me \\
\hline Compliance & 31 & 100 & 67.71 & 63 & 56 & 100 & 83.82 & 81 & 63 & 100 & 80.18 & 81 \\
Identification & 43 & 100 & 85.06 & 86 & 57 & 100 & 91.49 & 96 & 50 & 100 & 86.71 & 89 \\
Internalization & 64 & 100 & 87.82 & 91 & 69 & 100 & 92.02 & 96 & 70 & 100 & 89.12 & 91 \\
\hline
\end{tabular}

Analysis of the influence of Peer Teaching by RCA method toward the obedience of executor nurse on reporting the patient safety incident in Mataram Hospital before and after Peer Teaching conducted was showed at Table 3.

Table 3 The result of Bivariate Test by Wilcoxon at Pre Intervention Group, Post Intervention 1 and Post Intervention 2 Groups $(n=51)$

\begin{tabular}{|c|c|c|c|c|}
\hline & & $\mathrm{N}$ & Mean Rank & $\mathrm{p}$ value \\
\hline \multirow[t]{2}{*}{ Pre compliance - post 1 compliance } & Negative Rank & 7 & 16.64 & 0.000 \\
\hline & Positive Rank & 42 & 26.39 & \\
\hline \multirow[t]{2}{*}{ Pre identification - post 1 identification } & Negative Rank & 14 & 19.89 & 0.004 \\
\hline & Positive Rank & 32 & 25.08 & \\
\hline \multirow[t]{2}{*}{ Pre internalization- post 1 internalization } & Negative Rank & 18 & 22.78 & 0.028 \\
\hline & Positive Rank & 32 & 27.03 & \\
\hline \multirow[t]{2}{*}{ Pre compliance - post 2 compliance } & Negative Rank & 7 & 19.79 & 0.000 \\
\hline & Positive Rank & 40 & 24.74 & \\
\hline \multirow[t]{2}{*}{ Pre identification - post 2 identification } & Negative Rank & 20 & 21.68 & 0.343 \\
\hline & Positive Rank & 25 & 24.06 & \\
\hline \multirow[t]{2}{*}{ Pre internalization- post 2 internalization } & Negative Rank & 23 & 24.54 & 0.481 \\
\hline & Positive Rank & 27 & 26.31 & \\
\hline \multirow[t]{2}{*}{ Post 1 compliance - post 2 compliance } & Negative Rank & 25 & 23.24 & 0.104 \\
\hline & Positive Rank & 17 & 18.94 & \\
\hline \multirow[t]{2}{*}{ Post 1 identification - post 2 identification } & Negative Rank & 30 & 24.97 & 0.003 \\
\hline & Positive Rank & 14 & 17.21 & \\
\hline
\end{tabular}

The result of this research shows that there are influence between Peer Teaching method of study and the obedience of executor nurse on reporting the patient safety incident, with the different test value of indicator of compliance 0.000 , identification 0.004 , and internalization 0.028 . In the obedience score, the category of compliance (phase of emerge the willingness, motivate, wish the praise and fear to the punishment) shows score with the difference larger compared to the score of obedience of identification phase 
(phase of obedience reinforcement because of keeping the good relation with the superior and colleagues) and internalization phase (behavioral change phase because have emerged the awareness) on reporting the incident of patient safety.

This matter is strenghtened with the result of research which is done by Yin Chiang et al. (2011), it concluded that the culture of reporting the incident of patient safety which is perceived by nurse in Taiwan has a lot of influenced by attaching with the colleagues, communication between professional in the treatment room, and the working atmosphere of getting appreciation or without penalization. This Yin's research also mention that nurse perception in conducting of reporting is closely related with the awareness of risk from patient safety. At the phase of internalize becomes a culture in each self, every nurse requires more effort from the hospital management in Taiwan.

Besides that also, recommendation got from Kristensen et al., (2016) which expressing that in civilizing patient safety and peaceful gift caring needed by role from hospital management to improve the medical staff awareness through clinical leader in doing assessment objectively at the nurse performance in the case of patient safety. Furthermore, the party of hospital management can conduct the cultural development of patient safety continually.

Knowledge which is given recuringly is wished to be a reminder that can impact the increase of obedience with the end result is behavioral change on reporting the incident of patient safety. There are lot of study methods which can be passed to the nurse as an informal education on the chance of when their knowledge enhance, the obedience to perform rules has the same either. Compliance phase is the easiest obedience phase to be influenced, and the next phases are phase of identification and internalization with the intervence of peer teaching implementation.

The result of this research is also shows that there are difference of the obedience score of post intervence at indicator of pre compliance to post compliance 2 ( $p$-value 0.000). But, there is found no difference of obedience score at the category of pre identification to post identification 2 ( $p$-value 0.343 ), and pre internalization to post internalization 2 ( $p$-value 0.481). The analysis of statistical test indicates that the intervention of peer teaching only influenced the result of obedience score difference of compliance phase. However, at the phase of identification and internalization, there are no difference of obedience score appear.

Thus, at the result of Rank Table of Wilcoxon test, there is difference value of positive rank with the mean of 24.06 at pre identification and post 2 identification. This condition depict the increase of mean value although it is less than 10 points. The difference value also happened at pre internalization to post 2 internalization, by positive rank of 26.31. Its meaning is there is still an increase of the obedience mean value at the result of measurement after conducted the Peer Teaching. It is happened because the implementation of peer teaching is not been given to the second of 20 days, so there is no changes from the result of study.

Research conducted by Ekman, Petersson, Tågerud, and Bäckström (2012) reporting that there are still nurses who not report the undesirable incident of drug side effects of about $32 \%(n=453)$, those resulted due to the impression of assuming this condition as an insignificant mentioned to be reported. In addition to this, there is about $88 \%(\mathrm{n}=453)$ of nurses who are very interest to get a training about pharmacology in the case of security and monitoring of prevention of drug side effects because it can develop their career. This research suggests to the hospital management to keep on continue to give the related training of the mentioned above so that the reporting obedience can enhance.

The result of study is supported by the observation result which is found in the room, where there are observation functions done from the level of middle management 
that is committee of patient safety quality, up to the room head which have to be holistic. It will not only effect to the nurse obedience of motivate/ compliance categories, but also required the support management system so that the nurse obedience will increase at identification and internalization categories. The implementation of Peer Teaching toward nurse also can give the effective result if it accompanied with the motivation from executor nurse itself by giving the stimulation continually.

\section{CONCLUSION}

Giving of RCA method of Peer teaching has it own influence toward the obedience score of executor nurse on reporting the patient safety incident, all of it at compliance, identification and, internalization indicators. In the implementation, it is still found nurses which his/her obedience phase only at the Compliance category (Willingness Phase) on reporting the incident of patient safety. At the phase of identification (approved) and internalization (executed by awareness), a nurse has not yet been endured consistently.

\section{ACKNOWLEDGEMENT}

Appreciation is given to all parties who have contributed to this research. Researcher render thanks to the Director of RSUD Kota Mataram, my beloved parents, Mr. Suharmanto, Mrs. Faizah, Mrs. Devi, Mrs. Gusti Sinta, Mr. Dani, Mrs. Smy, and all of nurses which become the tutor of Peer Teaching, and also the respondents which have helped the process during the research take place.

\section{REFERENCE}

Charles, R., Hood, B., Derosier, J. M., Gosbee, J. W., Li, Y., Caird, M. S.\& Hatakenaka, S. (2016). How to perform a root cause analysis for workup and future prevention of medical errors: a review. Patient Safety in Surgery, 10(1), 20. https://doi.org/10.1186/s13037-016-0107-8

Chiang, H.-Y., Hsiao, Y.-C., Lin, S.-Y., \& Lee, H.-F. (2011). Incident reporting culture: scale development with validation and reliability and assessment of hospital nurses in Taiwan. International Journal for Quality in Health Care: Journal of the International Society for Quality in Health Care / ISQua, 23(4), 429-36. https://doi.org/10.1093/intqhc/mzr031

Ekman, E., Petersson, G., Tågerud, S., \& Bäckström, M. (2012). Awareness among nurses about reporting of adverse drug reactions in Sweden. Drug, Healthcare and Patient Safety, 4(1), 61-66. https://doi.org/10.2147/DHPS.S31103

Health, W. S. D. of. (2012). Adverse Event Reporting Program GUIDE: Root Cause Analysis Process, (October).

Hwa, T. T. (2009). Student Peer Teaching Strategy, Malaysia Case Studies from the AsiaPacific Region.

Kristensen, S., Túgvustein, N., Zachariassen, H., Sabroe, S., Bartels, P., \& Mainz, J. (2016). The virgin land of quality management: A first measure of patient safety climate at the National Hospital of the Faroe Islands. Drug, Healthcare and Patient Safety, 8, 49-57. https://doi.org/10.2147/DHPS.S100575

Ministry of Health (2008). Pedoman Pelaporan Insiden keselamatan Pasien (IKP) (Patient Safety Incident Report) (2nd ed.). Jakarta.

Niven, N. (2012). Health Psychology: An Introduction for Nurses and other Health Care Professionals (Indonesia Translation). Jakarta: EGC. pp 192-198. 